\title{
APLICAÇÃO DE CÉLULA DE PRODUÇÃO NO SERVIÇO DE EXECUÇÃO DE FACHADA: UM ESTUDO DE CASO NA CONSTRUÇÃO CIVIL
}

\section{PRODUCTION CELL IMPLEMENTATION IN THE FACADE EXECUTION: A CONSTRUCTION CASE STUDY}

\author{
Renato Nunes Mariz* E-mail: renatonunesmariz@ hotmail.com \\ Flávio Augusto Picchi* E-mail: fpicchi@lean.org.br \\ *Universidade Estadual Campinas (UNICAMP), Campinas, SP
}

\begin{abstract}
Resumo: A construção civil é um ambiente com alto índice de desperdício. A filosofia Lean pode trazer grande contribuição através de seu foco na eliminação dos desperdícios. Uma ferramenta muito utilizada na manufatura enxuta (lean) é a célula de produção, cujo principal objetivo é manter a produção o mais próximo possível do fluxo contínuo. Já no contexto da construção, as aplicações desta ferramenta são ainda embrionárias, despertando o interesse por seu maior estudo. O objetivo deste trabalho é analisar como foi aplicada uma célula de produção em um serviço de execução de fachada e avaliar os resultados obtidos. Para tanto, utilizou-se o método do estudo de caso em um fornecedor que executa fachadas para uma grande incorporadora. Foram coletados dados qualitativos (observações in loco e entrevista com funcionários) e quantitativos (dados de prazos e custos fornecidos pela construtora) para posterior análise dos mesmos, antes e pós implementação da célula de fachada. Através da revisão bibliográfica e análise da implantação identificou-se que foram introduzidas melhorias relacionadas a: a) métodos b) materiais c) mão de obra d) máquinas e equipamentos. Os resultados indicam melhoria na relação da administração com os funcionários, aumento do compromisso dos funcionários, redução de custos com mão de obra direta (pedreiros) e aumento da remuneração recebida pelos funcionários. Este trabalho contribui para expansão da utilização desta ferramenta (célula de produção) no contexto da construção registrando boas práticas e mostrando que através desta aplicação, benefícios significativos podem ser alcançados.
\end{abstract}

Palavras-chave: Célula de Produção. Lean Thinking. Construção.

Abstract: The construction industry is an environment with much waste. An alternative that could minimize this problem is Lean Thinking, as it focuses on eliminating waste. A widely used tool in lean manufacturing is the production cell, whose main goal is to keep production in continuo flow. In the construction context, the applications of this tool are still incipient, arousing the interest to be further investigated. The aim of this study is to analyze how a production cell was applied in a facade service execution and evaluate this result. We used the case study method in a contractor with experience in facades execution. We collected qualitative data (in situ observations and interviews with employees) and quantitative (time and cost data supplied by the contractor). After the data were analyzed (before and after cell implementation) Through analysis and literature review we decided to follow those steps: a) methods b) materials c) people d) equipments and machines. The results point out improvement in the employee relationship with the administration, increased employee commitment, cost savings with direct labor and increase the pay received by employees. This paper contributes to expanding the use of this tool (production cell) in the construction and shows that through this application, many benefits can be achieved.

Keywords: Production cell. Lean thinking. Construction.

Revista Produção Online, Florianópolis, SC, v.14, n. 2, p. 703-719, abr./jun. 2014. 


\section{INTRODUÇÃO}

\subsection{Contexto}

Dentre algumas restrições quanto ao desenvolvimento da construção civil brasileira, a baixa eficiência produtiva e qualidade e produtividade insatisfatória (MELLO, 2007) Costa e Formoso (1998) apontam que a construção civil contém inúmeros desperdícios, gerados pelas atividades que não agregam valor, com consequência de um processo de baixa qualidade que traz como resultado não somente a elevação de custo, mas também um produto de baixa qualidade.

Uma alternativa que pode modificar este panorama é o Lean Thinking que é uma generalização do Sistema Toyota de Produção, aplicável a vários setores (WOMACK; JONES, 1996). Esta filosofia baseia-se na eliminação dos desperdícios ao longo do fluxo de valor, deste modo encurtando os prazos (lead time), reduzindo os custos e também aumentando a qualidade do produto (OHNO, 1997).

Segundo Picchi (2003), existem inúmeras oportunidades de aplicação do Lean Thinking na construção, levando em consideração a aplicação dos conceitos, elementos e ferramentas desta filosofia.

\subsection{Justificativa}

Desde a proposição pioneira de Womack e Jones (1996) quanto aos 5 princípios do Lean Thinking (valor, fluxo de valor, fluxo contínuo, produção puxada e perfeição), o princípio de fluxo contínuo tem sido destacado como fundamental nesta filosofia. Para operacionalização deste princípio, uma ferramenta bastante utilizada na manufatura tem sido a célula de produção, que tem por objetivo manter o fluxo de produção o mais próximo do contínuo (LIKER, 2005).

Os benefícios trazidos pelas aplicações das células de produção na manufatura são: redução do tempo de setup, redução de estoque em processo, redução de lead time, redução de custos, redução de quantidade de material, aumento da qualidade do produto, simplificação da programação, entre outros (PATTANAICK; SHARTA, 2009).

Revista Produção Online, Florianópolis, SC, v.14, n. 2, p. 703-719, abr./jun. 2014. 
Já no contexto da construção, as aplicações desta ferramenta são ainda embrionárias, despertando o interesse por seu maior estudo. $O$ objetivo deste trabalho é analisar como foi aplicada uma célula de produção em um serviço de execução de fachada, bem como avaliar os resultados obtidos.

\section{REVISÃo BIBLIOGRÁFICA}

\subsection{Célula de Produção}

O fluxo contínuo é a produção de uma peça de cada vez (ou um lote pequeno de itens), sendo que cada item passa de um processo para o seguinte, sem interrupção. Ou seja, cada processo produz apenas o que é exigido pelo processo seguinte ou cliente final sem geração de estoque (ROTHER; SHOOK, 1999). Uma das maneiras de se conseguir o fluxo contínuo é através das células de produção (LIB, 2003)

As células de produção foram desenvolvidas para atender o incipiente mercado japonês e podem ser consideradas como uma evolução do conceito de linha de montagem de Ford (NARUSAWA; SHOOK, 2009).

Uma célula é um arranjo de pessoas (mão de obra), máquinas, materiais e métodos (4Ms), em que as etapas do processo estão próximas e ocorrem em ordem sequencial, através do qual as partes são processadas em fluxo contínuo (ou em alguns casos, de forma consistente com lotes pequenos mantidos em toda a sequência das etapas do processo), (ROTHER; HARRIS 2002).

Dias et al.. (2007) identificaram que uma empresa ao utilizar as células de produção, conseguiu reduzir o lead time e apresentaram custos consideravelmente diferenciados em relação ao método tradicional, deste modo, as mesmas podem trazer muitos benefícios para a empresa.

Segundo Hyer e Brown (1999), uma célula real deve apresentar duas características: (1) deve haver dedicação de recursos para uma mesma família de produtos e (2) é necessária a ligação em termos de tempo, espaço e informação entre pessoas e tarefas.

O layout celular em "U" é comum, pois evita que se percorram distâncias muito grandes e possibilita combinações diferentes de tarefas para os operadores

Revista Produção Online, Florianópolis, SC, v.14, n. 2, p. 703-719, abr./jun. 2014. 
(LIB, 2003). Slack et al. (1997), mostra as vantagens e desvantagens do layout celular (Quadro 1):

Quadro 1 - Vantagens e Desvantagens do layout celular

\begin{tabular}{|l|l|}
\hline - Vantagens & \multicolumn{2}{|c|}{ Desvantagens } \\
\hline $\begin{array}{l}\text { entre custo e flexibilidade para } \\
\text { operações com variedade } \\
\text { relativamente alta }\end{array}$ & - $\begin{array}{l}\text { Pode ser caro reconfigurar o } \\
\text { arranjo físico atual } \\
\text { Pode requerer capacidade } \\
\text { adicional }\end{array}$ \\
- Atravessamento rápido & - Trabalho em grupo pode dar \\
resultar em melhor motivação & $\begin{array}{l}\text { Pode reduzir níveis de utilização } \\
\text { de recursos }\end{array}$ \\
\hline
\end{tabular}

Fonte: Slack et al. (1997)

As práticas lean são mais fáceis de ser implementadas em células do que em linhas de montagem e layout funcionais, pois estas combinam em fluxo de operadores e equipamentos (SAURIM et al.., 2010). Pattanaick e Sharta (2009) reforçam esta idéia, pois estes autores relatam que o layout celular auxilia no alcance de muitos objetivos do Lean Thinking, já que ajuda na eliminação de atividades que não agregam valor (desperdícios), tais como: tempos de espera, gargalos, transportes e estoque em processo.

Black (1991) vai ainda mais longe, apontando que a criação de uma célula de produção é o primeiro passo rumo à conversão de uma fábrica comum para uma fábrica com futuro.

Além das aplicações das células nas operações de chão de fábrica, as mesmas têm grande potencial para transformar relações por toda a empresa, ou seja, podem ser utilizadas em alguns setores da organização que dão suporte à produção, como: planejamento, compras, engenharia e suprimentos (NYMAN, 1992). Este fato que é corroborado por Swank (2003) que relata que a célula de produção já está sendo aplicada no setor de serviços, onde as equipes criam fluxo em pequenos lotes e conseguem reduzir o estoque em processo.

Pampanelli, Found e Bernades (2013) analisaram a aplicação de células de produção sobre perspectivas das filosofia Lean e Green. Os autores concluíram que ao utilizar ambas abordagens, conseguiu-se reduzir os usos de recursos de $30 \%$ a $50 \%$.

Revista Produção Online, Florianópolis, SC, v.14, n. 2, p. 703-719, abr./jun. 2014. 


\subsection{Célula de produção na construção}

Ballard e Howell (1998) relatam que diferentemente da manufatura, onde produto passa pelas estações de trabalho, na construção as equipes trabalham em torno do produto (edificação), em decorrência de suas dimensões e peso. Devido a esta peculiaridade da construção, Santos et al. (2002) propôs um modelo de célula móvel de produção aplicado à construção para execução de dry-wall) conseguindo com esta aplicação diversos benefícios.

No setor de serviços relacionados à construção, apresentam-se alguns trabalhos, como: (REIS; PICCHI, 2004) aplicado a fase de fluxo de negócios antes e após a execução da obra e (WEINDORFER, 2001), (LIMA et al., 2009) e (AQUERE; CARVALHO; LIMA, 2012), aplicados à fase de projeto.

\section{MÉTODO}

A estratégia adotada nesta pesquisa foi o estudo de caso de caráter preponderantemente exploratório, realizado em um canteiro de obras de uma incorporadora (contratante) de nível nacional na cidade de Belém/PA durante o primeiro semestre de 2010 .

O serviço escolhido foi o revestimento fachada, pois era um serviço que estava sendo executado por uma construtora (contratada), que estava introduzindo a filosofia lean em seus canteiros. Essa empresa aplicou uma célula de produção no serviço de execução de fachada, o que possibilitou a coleta de dados qualitativos, através de observação in loco e entrevistas com funcionários, com objetivo de avaliar as modificações ocorridas após esta intervenção.

Também foram comparados serviços realizados por 6 balancins antes e após a implantação da célula. Para comparação destes resultados foram recolhidos os seguintes dados; os dados referentes a prazo foram medidos diariamente por um estagiário da construtora e os dados relacionados a custo foram avaliados quinzenalmente com o fechamento da folha de pagamento. Tanto os custos quanto os prazos foram avaliados antes da introdução da célula de produção (método tradicional de execução), planejado, e após a implantação da célula (efetivamente realizado).

Revista Produção Online, Florianópolis, SC, v.14, n. 2, p. 703-719, abr.jun. 2014. 
A partir da observação das modificações introduzidas pela empresa e da definição de célula proposta por Rother e Harris (2002), adotou-se uma classificação visando agrupar mudanças relacionadas quanto a seu relacionamento, são estes: a) métodos b) materiais c) mão de obra d) máquinas e equipamentos.

\section{RESULTADOS E DISCUSSÕES}

\subsection{Métodos}

Nesta fase, a construtora planejou as atividades relacionadas à execução da fachada. Deste modo, foram gerados os seguintes documentos:

- Linha de balanço da fachada: com base nos índices de produtividade do histórico da empresa e nos quantitativos relacionados à fachada, chegou-se aos prazos de cada atividade para cada balancim;

- Layout do pavimento da central de argamassa (anexo A): neste a construtora procurou planejar um estoque padrão para cada insumo dos serviços relacionados à fachada (cimento, areia e cal). Também foram projetados os lugares que ficariam os misturadores de argamassa. Além disso, a construtora também atentou para a questão da logística do material projetando ruas de fluxos por onde os materiais deveriam ser transportados;

- Pacotes de serviço da fachada: os quais contêm as atividades que os pedreiros deverão executar e também os valores pagos por cada atividade executada, sendo este distribuído para cada pedreiro. A incorporadora já dispunha de um conjunto de especificações técnicas, que foram utilizadas para padronizar a execução dos serviços do pacote.

Passada a fase de planejamento, os serviços iniciaram e após 3 meses a empresa modificou o fluxo de informação introduzindo algumas ferramentas, particularmente o kanban, que será descrito no item 4.2 materiais e ferramentas de controle visual para facilitar o fluxo da informação, dentre as quais:

- Documentos usados no planejamento, tais como: linha de balanço, planta do layout do pavimento da central de argamassa (anexo A) e pacotes de serviço; 
- Placas indicativas, por exemplo: para dosar traços de argamassa e para indicar a rua de fluxo de materiais (Figura 1);

- Quadro emocional: o qual mostrava o estado emocional (bom, regular, ruim, ausente ou doente) de cada funcionário. Este ficava localizado em um local acessível e de fácil acesso a todos os funcionários da obra, pois o mesmo localizava-se no refeitório da obra;

- Farol da fachada: este era utilizado para o controle dos serviços de execução da fachada e ficava na sala de engenharia, de tal forma que todos os funcionários da administração acompanhavam o andamento da execução da fachada.

Figura 1 - Placas indicativas

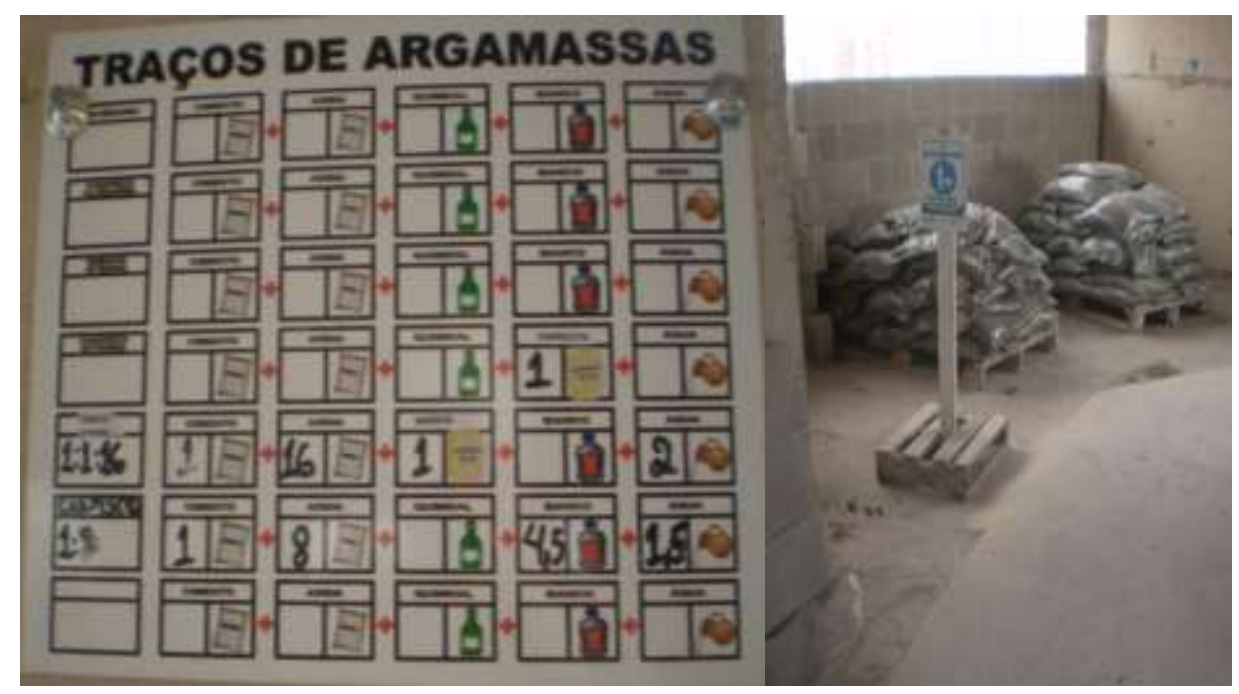

Ainda nesta fase adotou-se o uso do programa 5's (senso de organização, senso de utilização de espaço, senso de limpeza, senso de autodisciplina e senso de padronização) no pavimento da central de argamassa, já que a organização e disposição dos materiais neste pavimento ficava sobre responsabilidade da construtora (Figura 2). 
Figura 2 - Antes e Depois no pavimento da central de Argamassa (Senso de Utilização de Espaço e Organização)
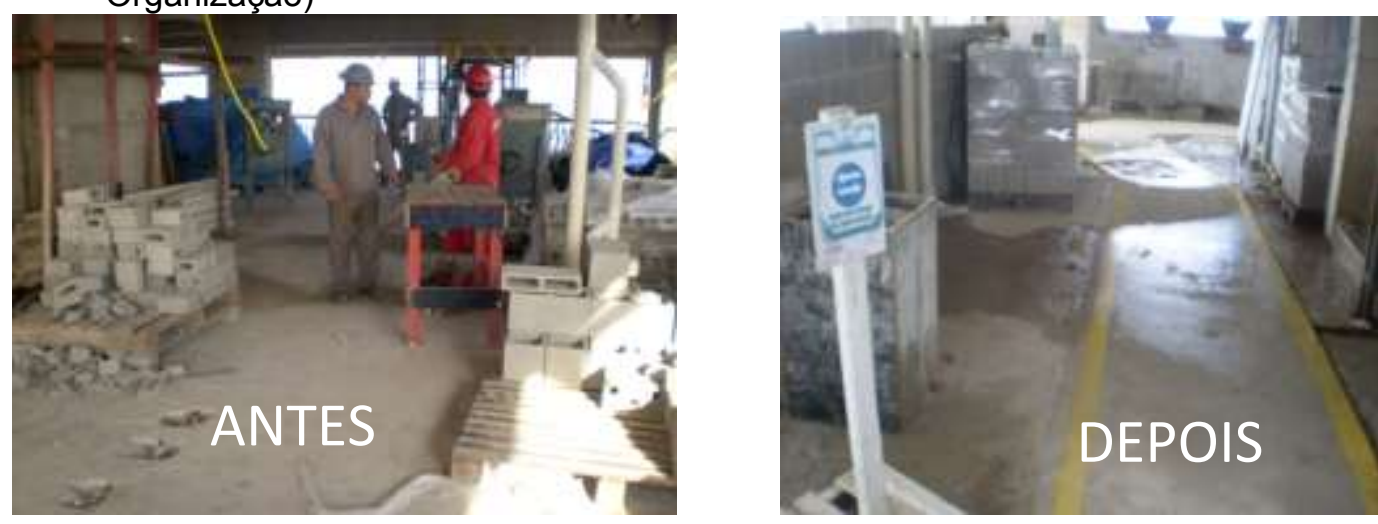

\subsection{Materiais}

A contratante projetou um layout de canteiro que permitiu que o transporte de materiais fluísse praticamente sem interrupções, principalmente os necessários para execução dos serviços de fachada, pois assim que o material chegava, este era alocado em paletes e transportado por carrinhos mecânicos para o guincho que estocava o material no pavimento planejado (Figura 3 ). No caso dos materiais necessários para execução da fachada, o guincho estocava o cimento, areia e cal no último pavimento.

Figura 3 - Fluxo de materiais para a execução da fachada

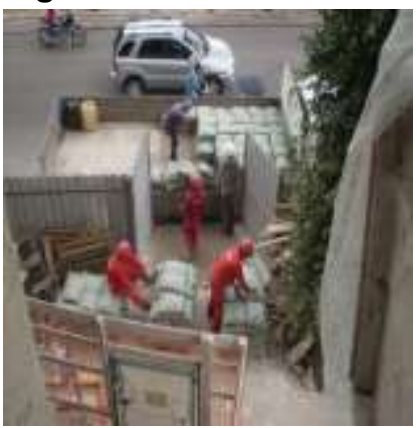

Recebimento e colocação em paletes



Transporte horizontal

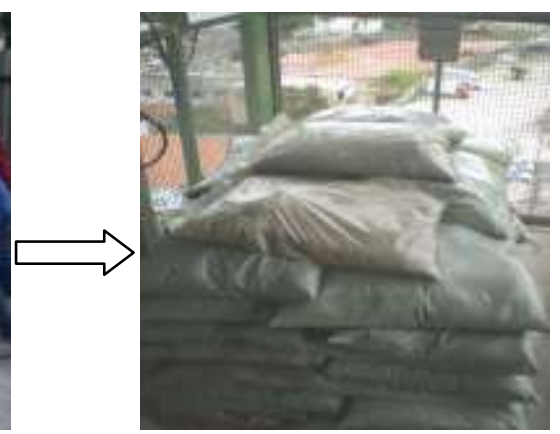

Transporte Vertical

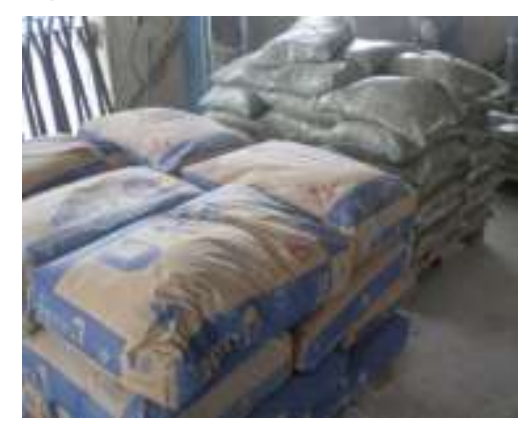

Estoque de Segurança

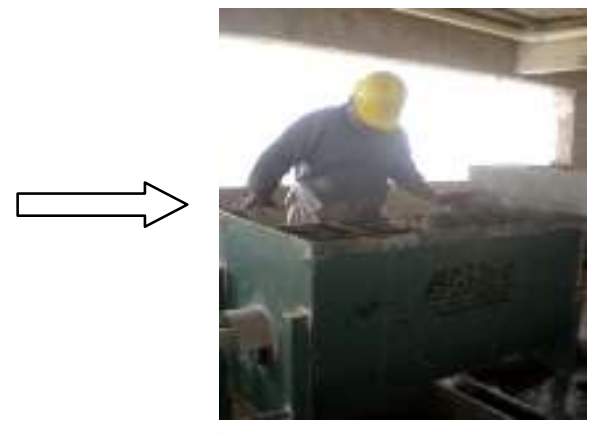

Produção da argamassa

Revista Produção Online, Florianópolis, SC, v.14, n. 2, p. 703-719, abr./jun. 2014. 
É importante ressaltar que todos estes insumos eram entregues ensacados pelo fornecedor, deste modo conseguiu-se estocar os materiais ao lado da produção. Para a produção de argamassa foi introduzido o conceito de fluxo puxado. Assim sendo, os funcionários da produção recebiam no dia anterior a produção quantos kanbans ${ }^{1}$ fossem necessários para o dia seguinte. Antes de começar o dia de trabalho os funcionários distribuíam os kanbans de acordo com as necessidades de execução do serviço, em um quadro denominado quadro de nivelamento. Este quadro identificava o horário no qual o funcionário iria precisar do traço e o pavimento em que este funcionário estaria.

$\mathrm{O}$ operador da betoneira analisava os pedidos de argamassa no quadro e nivelava os mesmos de modo que um funcionário não recebesse vários traços enquanto outro ficasse esperando. Ao final do dia o operador passava os dados para uma planilha, que ao final da semana era recolhida e analisada pelos estagiários da construtora.

Em relação à distribuição de argamassa, foi realizado um processo inovador na construtora. A argamassa após ser dosada era despejada em funis no último pavimento, que eram conectados a tubos flexíveis que posteriormente transportavam a argamassa até os balancins (Figura 4). Através da adoção destes equipamentos conseguiu-se economizar tempo de utilização do guincho e mão de obra para transporte de argamassa.

Figura 4 - Funil e tubo para transporte de argamassa para os balancins

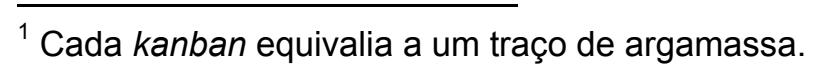

Revista Produção Online, Florianópolis, SC, v.14, n. 2, p. 703-719, abr./jun. 2014. 


\subsection{Mão de obra}

Na tentativa de eliminar desperdícios inerentes ao fluxo de operários, foram adotadas algumas medidas, como: utilização de tubos para a distribuição de argamassa, a utilização de rádio transmissor e a disponibilização de bebedouros em pavimentos intermediários e no pavimento da central de argamassa.

Além disso, os trabalhadores foram estimulados a desempenhar um melhor trabalho, pois foi criado um prêmio para os funcionários que tiveram maior produtividade no mês, o que gerou uma disputa salutar entre os operários.

Também com o mesmo intuito, a construtora criou o prêmio funcionário do mês, este que consistia em determinado valor, entregue em materiais de construção.

A construtora passou a promover eventos internos e externos de modo a melhorar as relações interpessoais entre os funcionários das obras e da administração, como: aniversariantes do mês, confraternizações e participação dos funcionários em campeonatos de futebol.

Os próprios funcionários alegaram uma melhoria na transparência dos processos entre eles e a administração após a aplicação da célula de produção.

\subsection{Máquinas e equipamentos}

A construtora introduziu algumas mudanças com relação aos equipamentos. Algumas destas já citadas anteriormente, como: a disponibilização de rádio transmissor para funcionários; equipamentos necessários para a produção de argamassa foram levados para o último pavimento (central de argamassa); a utilização de funis e tubos para transporte de argamassa direto para os balancins e a utilização de carrinhos mecânicos para transporte de paletes.

Outra melhoria foi o aluguel de misturadores de argamassa que tinham rodas para facilitar seu transporte.

\subsection{Avaliação econômica dos resultados obtidos com a introdução da célula}


Neste item serão mostrados os comparativos de custos de mão de obra direta realizados em método tradicional (antes da aplicação da célula), o planejado e o efetivamente realizado (após a implementação da célula).

\subsubsection{Custo de mão de obra em método tradicional}

Antes da implantação da célula, o prazo de execução do pavimento era de 4 dias. O valor diário era de $R \$ 43,45$, referente ao salário de carteira de $R \$ 730,00$ mais $25 \%$ de adicional de periculosidade dividido por 21 dias úteis.

$\mathrm{Na}$ Tabela 1 foi considerado o custo não apenas com a mão de obra direta (pedreiros), mas também com vale transporte, alimentação e encargos sociais.

Tabela 1 - Custo da mão de obra de método tradicional

\begin{tabular}{cccccc}
\hline Itens & $\begin{array}{c}\text { Total de } \\
\text { Pavimentos }\end{array}$ & $\begin{array}{c}\text { Total de } \\
\text { Pedreiros }\end{array}$ & $\begin{array}{c}\text { Total de } \\
\text { dias da } \\
\text { Equipe }\end{array}$ & $\begin{array}{c}\text { Custo } \\
\text { diário }\end{array}$ & Total Pago \\
\hline $\begin{array}{c}\text { Mão de obra } \\
\text { direta }\end{array}$ & 29 & 6 & 4 & $\mathrm{R} \$ 43,45$ & $\mathrm{R} \$ 30.242,86$ \\
$\begin{array}{c}\text { Transporte } \\
\text { Alimentação }\end{array}$ & 29 & 6 & 4 & $\mathrm{R} \$ 3,70$ & $\mathrm{R} \$ 2.575,20$ \\
$\begin{array}{c}\text { Encargos } \\
\text { Sociais }\end{array}$ & 29 & 6 & 4 & $\mathrm{R} \$ 6,80$ & $\mathrm{R} \$ 4.732,80$ \\
\\
Custo Total Método Tradicional para a execução da Fachada & $\mathbf{R} \$ \mathbf{7 5 . 3 5 4 , 4 3}$ \\
\hline
\end{tabular}

\subsubsection{Custo de mão de obra planejado}

Na fase de planejamento foi estabelecido que para um dia útil de um pedreiro, seria pago o valor de $R \$ 81,55$, representando um premiação de produtividade de $87 \%$ para os pedreiros que cumprissem o prazo de 2 dias por pavimento, caso a execução fosse concluída em menos de 2 dias seria pago este valor, no sistema de pagamento conhecido em canteiro de obras como por tarefa. 
Tabela 2 - Custo da mão de obra em fluxo planejado

\begin{tabular}{cccccc}
\hline Itens & $\begin{array}{c}\text { Total de } \\
\text { Pavimentos }\end{array}$ & $\begin{array}{c}\text { Total de } \\
\text { Pedreiros }\end{array}$ & $\begin{array}{c}\text { Total de } \\
\text { dias da } \\
\text { CP }\end{array}$ & $\begin{array}{c}\text { Custo } \\
\text { diário }\end{array}$ & Total Pago \\
\hline $\begin{array}{c}\text { Mão de obra } \\
\text { direta }\end{array}$ & 29 & 6 & 2 & $\mathrm{R} \$ 81,55$ & $\mathrm{R} \$ 28.378,57$ \\
$\begin{array}{c}\text { Transporte } \\
\text { Alimentação }\end{array}$ & 29 & 6 & 2 & $\mathrm{R} \$ 3,70$ & $\mathrm{R} \$ 1.287,60$ \\
$\begin{array}{c}\text { Encargos } \\
\text { Sociais }\end{array}$ & 29 & 6 & 2 & $\mathrm{R} \$ 6,80$ & $\mathrm{R} \$ 2.366,40$ \\
\multicolumn{7}{c}{ Custo Total Planejado para a CP-Fachada } & $\mathrm{R} \$ \mathbf{6 7 . 5 0 5 , 7 9}$ \\
\hline
\end{tabular}

\subsubsection{Custo de mão de obra efetivamente realizado}

Após a implementação da célula de produção, além de benefícios qualitativos, mostrados anteriormente, benefícios quantitativos também foram alcançados.

O tempo de ciclo reduziu em $25 \%$ em relação ao planejado e $62,5 \%$ comparativamente ao executado em método tradicional, ficando para as atividades de chapisco e emboço a média de 1,5 dias/pavimento, o que trouxe uma significativa economia para a empresa e ganhos também para os funcionários, ficando bem evidente a eficácia da prática da relação Ganha x Ganha (Tabela 3). Os funcionários concluíam o serviço em 1,5 dias, porém recebiam o equivalente aos 2 dias pela tarefa concluída.

Tabela 3 - Custo da mão de obra efetivamente realizada

\begin{tabular}{|c|c|c|c|c|c|}
\hline Itens & $\begin{array}{c}\text { Total de } \\
\text { Pavimentos }\end{array}$ & $\begin{array}{l}\text { Total de } \\
\text { Pedreiros }\end{array}$ & \begin{tabular}{|c|} 
Total de \\
dias da CP
\end{tabular} & $\begin{array}{l}\text { Custo } \\
\text { diário }\end{array}$ & Total Pago \\
\hline $\begin{array}{c}\text { Mão de obra } \\
\text { direta }\end{array}$ & 29 & 6 & 2 & $\mathrm{R} \$ 81,55$ & $\mathrm{R} \$ 28.378,57$ \\
\hline Transporte & 29 & 6 & 1,5 & $\mathrm{R} \$ 3,70$ & $\mathrm{R} \$ 965,70$ \\
\hline Alimentação & 29 & 6 & 1,5 & $\mathrm{R} \$ 6,80$ & $\mathrm{R} \$ 1.774,80$ \\
\hline $\begin{array}{l}\text { Encargos } \\
\text { Sociais }\end{array}$ & 29 & 6 & 1,5 & $\mathrm{R} \$ 101,93$ & $\mathrm{R} \$ 26.604,91$ \\
\hline \multicolumn{5}{|c|}{ Custo Total Efetivamente Realizado para a CP-Fachada } & R\$ 57.723,98 \\
\hline
\end{tabular}

Ao final do estudo comparativo, foi elaborado um gráfico que mostra de modo bem evidente os ganhos de ambas as partes obtida pela aplicação da célula de produção no serviço de execução de fachada (vide Figura 5).

Revista Produção Online, Florianópolis, SC, v.14, n. 2, p. 703-719, abr./jun. 2014. 
Figura 5 - Comparação da Remuneração Mensal e Custo por Pavimento com mão de obra diretarevestimento da fachada

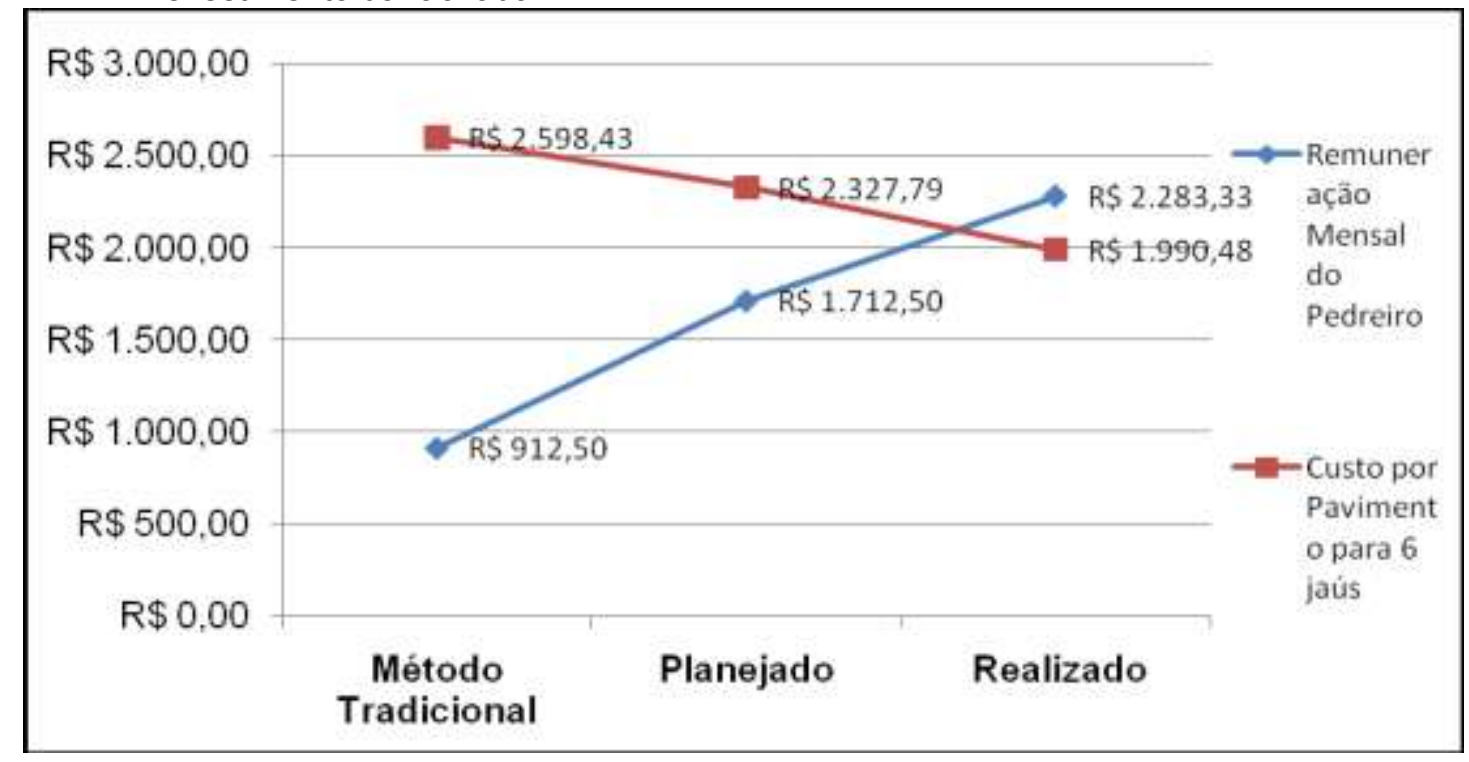

Pode-se perceber ao analisar a Figura 5, as vantagens financeiras obtidas através da aplicação da célula de produção nos serviços de fachada, fato este que pode ser observado ao compararmos a remuneração mensal dos funcionários que passou de $\mathrm{R} \$ 912,50$ para $\mathrm{R} \$ 2.283,33$, o que representa um ganho de $150 \%$.

Em contrapartida, a construtora diminuiu o custo por pavimento com mão de obra direta de $\mathrm{R} \$ 2.598,43$ para $R \$ 1.990,48$, economizando ao final da execução do chapisco e emboço, um total de $\mathrm{R} \$ 17.630,45$ com mão de obra direta, o que representa uma redução de $23 \%$, em relação ao custo inicial.

\section{CONCLUSÕES}

Foram observadas melhorias em relação aos 4 M's (métodos, materiais, mão de obra, e máquinas e equipamentos. Através das melhorias no fluxo de informação, por meio de algumas ferramentas, os funcionários passaram a assimilar as informações com maior rapidez e também houve mais transparência na relação entre administração e funcionário.

A modificação no layout do pavimento da central foi fundamental para conseguir uma melhor disposição dos materiais. Além disso, o programa 5's deixou o pavimento da central de argamassa mais organizado e limpo. 
Houve também benefícios significativos em relação ao transporte de materiais, pois através de práticas adotadas pela construtora, conseguiu-se uma maior fluidez no transporte, tanto da matéria prima utilizada para a produção de argamassa, quanta para a argamassa já dosada.

Em relação à mão de obra, houve algumas eliminações de desperdícios de movimentação e transporte, através de medidas simples, podendo ser destacado o processo de transporte de argamassa dosada por funis e tubos direto para os balancins.

Por meio das práticas de premiações, o funcionário foi estimulado a desempenhar um melhor trabalho, além disso, com a implementação da célula, o ambiente de trabalho passou a ser mais amistoso, pois a necessidade do trabalho em equipe ficou visível, trazendo um compromisso maior dos funcionários com a empresa.

Os benefícios financeiros foram relevantes, tanto para a empresa, que teve uma redução de custo de mão de obra direta de $23 \%$, quanto para os funcionários, que obtiveram um aumento na remuneração mensal de $150 \%$, já que através da aplicação da célula, houve redução no tempo de ciclo de execução da fachada.

O estudo, embora exploratório, aponta o potencial de aplicação das células de produção na construção, assim como algumas boas práticas que podem ser utilizadas na introdução das mesmas.

\section{AGRADECIMENTOS}

Ao CNPq pela bolsa de pesquisa concedida ao primeiro autor deste artigo e ao LAGERCON (LABORATÓRIO DE GERENCIAMENTO DA CONSTRUÇÃO).

\section{REFERÊNCIAS}

AQUERE, A.L; CARVALHO, J.D; LIMA, R.M. Project Cell: Cellular Organization of the Building Design Process. Journal of Construction Engineering and Management, v. 139, n. 5 p. 538-546, 2013. http://dx.doi.org/10.1061/(ASCE)CO.1943-7862.0000590

BALLARD, G; HOWELL, G. What kind of production is construction? In: ANNUAL CONFERENCE OF THE INTERNATIONAL GROUP FOR LEAN CONSTRUCTION, 6., 1998, Guarujá, Brazil. Proceedings... Brazil, 1998. 
BLACK, J T. The design of the factory with a future. New York. McGraw-Hill, 1991.

COSTA, A.L; FORMOSO, C.T. Perdas na construção civil: conceitos, classificações e seu papel na melhoria do setor. In: ENCONTRO NACIONAL DE TECNOLOGIA DO AMBIENTE CONSTRUÍDO, 1998, Florianópolis, Santa Catarina. Anais...

Florianópolis: UFSC/ANTAC, 1998.

Dias, S.L.V. et al. Alinhamento entre sistemas de produção, custo e indicadores de desempenho: um estudo de caso. Revista Produção Online, v.7, n.2 p. 144-169, 2007. http://dx.doi.org/10.14488/1676-1901.v7i2.72

HYER N. L.; BROWN K. A. The Discipline of Real Cells. Journal of Operations Management, v.17, n. 5 p. 557-574, 1999.

http://dx.doi.org/10.1016/S0272-6963(99)00003-0

LEAN INSTITUTE BRASIL (LIB). Léxico Lean. Glossário ilustrado para praticantes do pensamento lean. Tradução de Lean Institute Brasil. São Paulo: Lean Institute Brasil, 2003.

LIKER, J. O Modelo Toyota: 14 princípios de gestão do maior fabricante do mundo. Porto Alegre. Bookman, 2005.

LIMA, M.M.X; BISIO, L.R.A; ALVES, T.C.A. Mapeamento do fluxo de valor do projeto executivo de arquitetura em um órgão público. .In: SBQP 2009. São Carlos. Anais... ANTAC, 2009.

MELLO, L. C. B. B. Modernização das pequenas e médias empresas de construção civil: impactos dos programas de melhoria da gestão da qualidade. 2007. Tese (Doutorado em Engenharia Civil) - Programa de Pós Graduação em Engenharia de Civil, Universidade Federal Fluminense. Niterói-RJ, 2007.

NARUSAWA, T; SHOOK, J. Kaizen express: fundamentos para sua jornada lean. Tradução de Lean Institute Brasil. São Paulo: Lean Institute Brasil, 2009.

NYMAN, L.R. Making manufacturing cells work. Dearborn. American Society of Manufacturing Engineers, 1992.

OHNO, T. O sistema toyota de produção: além da produção em larga escala. Porto Alegre: Bookman, 1997. 150 p.

PATTANAIK, L.N; SHARMA, B.P. Implementing lean manufacturing with cellular layout:a case study. International Journal of Advanced Manufacturing Technology, v. 42, n. 7-8 p.772-779, 2009.

http://dx.doi.org/10.1007/s00170-008-1629-8 
PAMPANELLI, A.B; FOUND, P; BERNADES, A.M. A Lean \& green model for a production cell. Journal of Cleaner Production. p. 1-12. 2013.

PICCHI, F. A. Oportunidades da aplicação do Lean Thinking na construção. Revista Ambiente Construído, Porto Alegre, v. 3, n. 1, p. 7-23, jan./mar. 2003.

REIS, T; PICCHI, F.A. Identificação de desperdícios através de ferramentas de lean thinking aplicadas a estudos de caso do fluxo de negócios. In: ENTAC 2004. São Paulo. Anais... ANTAC, 2004.

ROTHER, M.; HARRIS, R. Criando fluxo contínuo: um guia de ação para gerentes, engenheiros e associados da produção. 1 ed. São Paulo, Brasil: Lean Institute Brasil, 2002. 103 p.

ROTHER, M.; SHOOK, J. Aprendendo a enxergar: mapeando o fluxo de valor para agregar valor e eliminar o desperdício. 1 ed. São Paulo: Lean Institute Brasil, 1999.

SANTOS, A; MOSER, L; TOOKEY, J.E. Applying the concept of mobile cell manufacturing on the drywall process. In: ANNUAL CONFERENCE OF THE INTERNATIONAL GROUP FOR LEAN CONSTRUCTION, 10., 2002. Gramado, Brazil. Proceedings... Brazil, 2002.

SAURIN, T. A; MARODIN, G. A; RIBEIRO, J.L.D. A framework for assessing the use of lean production practices in manufacturing cells. International Journal of Production Research, v.49, n. 11 p. 3211-3230, 2010. http://dx.doi.org/10.1080/00207543.2010.482567

SLACK, N. et al. Administração da produção. São Paulo: Atlas, 1997. 726p.

SWANK, C.K. The lean service machine. Harvard Business Review. p. 123 - 129, oct., 2003.

WEINDORFER, A. Melhorias de produtividade na secretaria de obras públicas do estado do Rio Grande do Sul. 2001. Mestrado (Dissertação de Mestrado) Universidade Federal do Rio Grande do Sul, 2001.

WOMACK, J. P.; JONES K. T.; ROSS, D. A máquina que mudou o mundo. 1 ed. Rio de Janeiro, Brasil: Campus, 1996. 332 p.

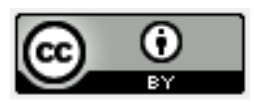

Artigo recebido em 10/12/2012 e aceito para publicação em 30/03/2014. DOI: http://dx.doi.org/10.14488/1676-1901.v14i2.1499 
ANEXO A: Layout do pavimento da central de argamassa
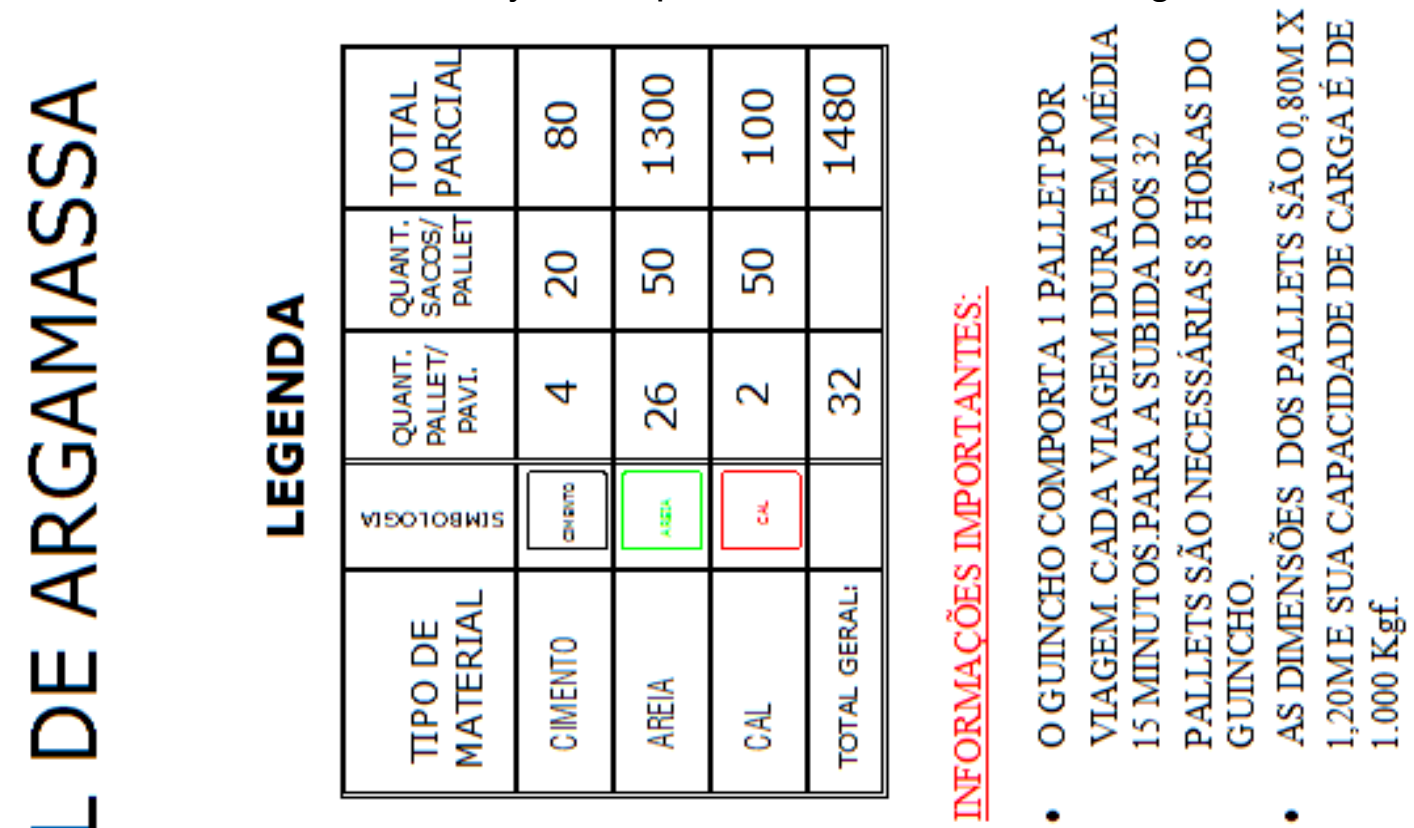

$\frac{\bar{\gamma}}{\frac{1}{}}$



$\frac{7}{8}$

○

$\frac{5}{5}$

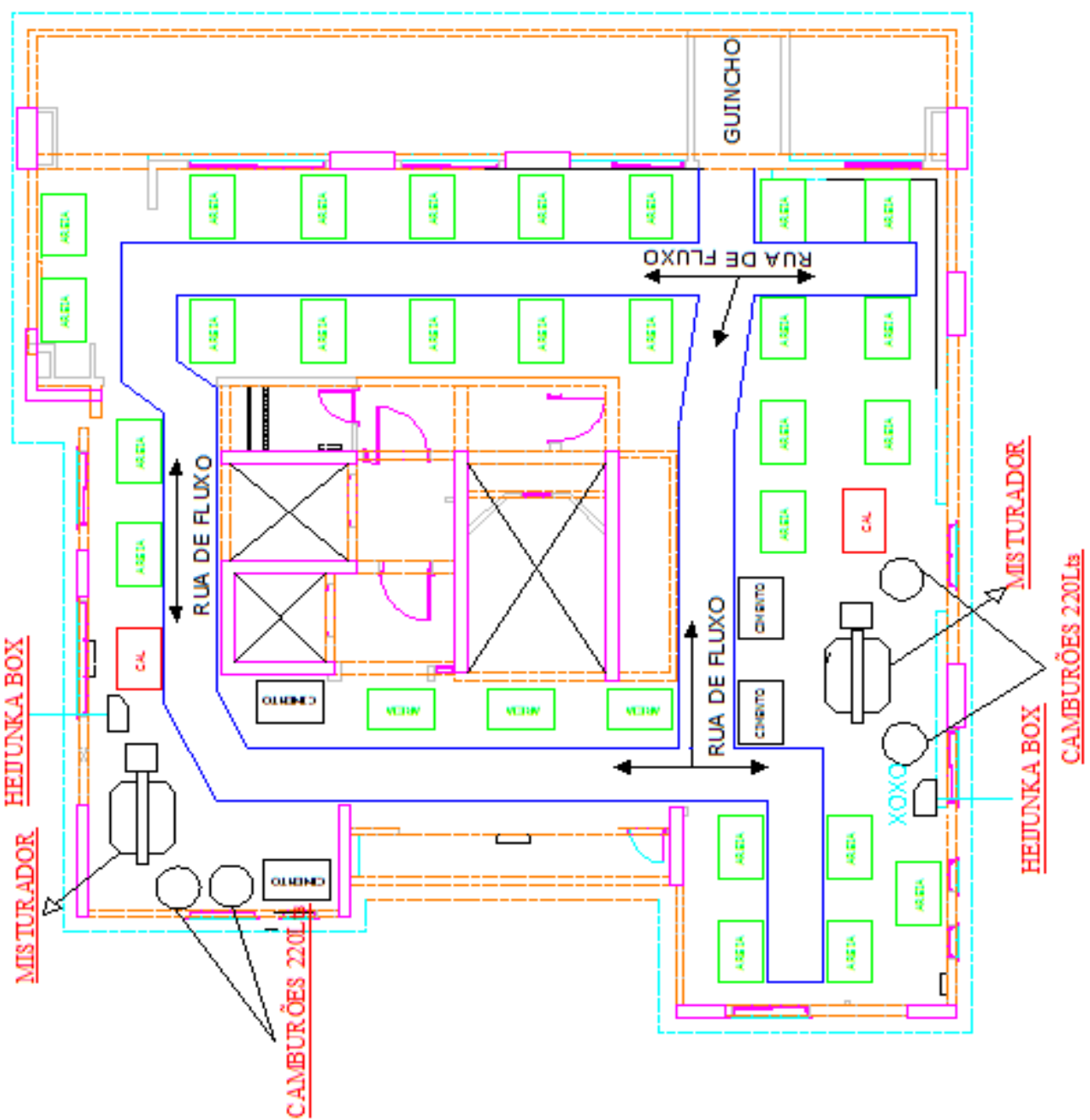

Revista Produção Online, Florianópolis, SC, v.14, n. 2, p. 703-719, abr./jun. 2014. 